\title{
Sport and Social Deviations - a Prognostic Attitude
}

\author{
Jerzy Kosiewicz
}

Josef Pilsudski University of Physical Education in Warsaw, Poland

\section{ABSTRACT}

The author focuses his attention first of all on social deviations which play a negative role in highly competitive sport. He tries to define - from the viewpoint of philosophy - how they will influence its future form.

He proclaims that in philosophy there are at least two options:

a. the one negating justifiability of philosophical statements on the future,

b. the one affirming that justifiability - after Aurelius Augustine and Hegel.

The author takes into account the second viewpoint and comes to the conclusion that as a philosopher (not a futurologist) he has the right to formulate hypothetical statements (referring to assumptions of the metaphysical hypothesis) on the influence of deviations on sport in the future.

He pays attention first of all to increasing aggression - both in forms permitted and not permitted by the regulations - and the growing number of injuries among athletes. He maintains that both those injuries as well as phenomena connected with commercialization - such as reification, atomization and alienation (constituting reasons for possible disorders in the field of physical, mental and relational health) will contribute to worsening the image and deformation of sense and essence neither of sport as such, nor of particular sports. This also applies to corruption, poaching, fans' frustration and aggression, doping, alcoholism and nicotinism.

He maintains also that social deviations coming from political, ideological, religious, racial and other similar factors will be less and less significant (admittedly they will not disappear, but their number and influence will be considerably limited).

\section{Philosophy and the future - two options}

While considering issues concerning the future of sport you may take into consideration at least two options. The first is that it is impossible - in the philosophical sense - to determine the future of sport. It is impossible, among others, because of the fact that in the moment of their formulation the statements which describe, determine and evaluate the future are neither true, nor false, because futurological propositions - similarly to mythical or mythological messages, the oral ones or those written in holy books - do not refer to real time and space. They refer to the non-illuminated future, to 
space-time phenomena, facts or data which do not exist yet. They are not subject to criteria of logical truth or false because their content refers to something which is only to come into existence and which does not exist yet. Hence they are neither true, nor false from the viewpoint of cognitive claims.

Philosophy in general and various specialized philosophies - including the philosophy of sport do not and have not had any particular obligations towards the future. If any obligations appeared in the form of significant, or even imperative, obligations, we would rather have to do with an ideology persuading for deeds - that is, with a quasi-theoretical and practical activity - and not with philosophy as a cognitive science.

Nevertheless, and on the other hand, it may be assumed that specialized sciences - especially practical ones - do plan what may, is to or should happen in the future. This applies to both natural sciences (such as, for example, medicine and the connected therapies) and to social sciences (among others, to pedagogy and its ideals).

For example, in natural sciences, social sciences or the humanities leaving aside formal sciences (Kosiewicz 2009b) it is recommendable to formulate hypotheses of prognostic values which belong to nomotetic inquiries. They constitute also a significant quality of each of the abovementioned methodological types of sciences. Explanation is the most important and - in my opinion - the final, in the teleological sense, function of each science. All other functions - like, for example, the formal one, the descriptive ones, the comparative ones, the holistic ones, the analytical ones, the synthetic ones, the axiological one - are gradual functions. From the content-related and the methodological point of view they are subject to nomotetic or nomological actions.

Prognostic hypotheses, and explanation referring to them, are connected with determining the future - that is, with what is going to happen then or, in other words, what may happen then. Of course it is better when a hypothesis is formulated in the form of an indicative - and not of a conditional statement.

The abovementioned hypotheses may refer to statements from the field of natural sciences, they may also have a historiosophic character: refer to supposed events or social changes.

In the history of philosophy, and especially in social philosophy, we have to do with, among others, two such conceptions which refer to providence. Aurelius Augustine, for example - confusing the protohistorical (mythical) order with the historical one, and the theological one with the philosophical one - was of the opinion that history of the world is connected with a soteriological conflict which underlies struggle between the mundane state and the divine state. Those who will not take sides with divine providence will face eternal damnation and perdition, whereas those who have been granted God's grace and who belong to the divine state will experience eternal happiness. Aurelius Augustine's historiosophy assumes that this judgment and the final post-Christ division is the final point of time when social changes and history come to a definite and irrevocable end.

On the other hand, in Hegel's view there appear historiosophical views which assume - with a similar certainty as in Augustine's case - that social changes, lots of nations and states have progressed and will progress in the direction he predicts as a manifestation of exteriorization and development of the spirit of the world (Hegel assumed that "universal history is underlain by some definite aim in itself and for itself, and that it really has been realized and is being realized - as a plan of Providence - or that generally reason is present in history" (Hegel 1990, p. 542).

Those philosophers' views may be also treated as suppositions, hypotheses concerning possible changes, including social ones. The discussed hypotheses have not, however, met their authors' - and their followers' - expectations. The future has not confirmed them. The suppositions - that is, 
historiosophic hypotheses - have not proved correct. This has not, however, exerted a negative influence on evaluation and greatness of their ideas and of the connected philosophical contexts of justification.

If the second viewpoint is assumed to be correct or sensible, this means, as I suppose, that there are no obstacles to set about - without coming into conflict with, for example, Augustinian or Hegelian logic, or with methodological assumptions concerning hypotheses from the field of the humanities (including those which are attributed with qualities of a metaphysical character typical for speculative philosophies (Kosiewicz 2009b) - set about considering the future of sport. Nota bene, logic (and specialized methodology which is based on it) which was used by the abovementioned thinkers, was mediated by Aristotelian logic, similarly to my suppositions concerning sport.

\section{Selected social deviations and sport}

One of more important issues, which is paid attention especially by sociologists, pedagogues, psychologists and philosophers, are social deviations, because they pose - and will continue to pose a considerable threat to sport. The athletes who are involved in everyday practice of sports life transfer (and are going to transfer) social anti-norms and anti-values, which are shaped during the training process and competitions on various levels, to sport based on high qualifications (highly competitive, professional, spectacular or Olympic) doing it in an automatic and uncritical way. It is going to happen, because an opinion pointing out that sport - and especially sport based on high qualifications - is situated beyond moral good and evil, which is anyway sensible from the pragmatic viewpoint, is going to become more and more popular. Hence we may assume that sport of such a type, determined by high income and other significant many-sided forms of success, will become a carrier of social deviations to an ever greater degree.

Social values based on political, ideological, religious, racial and other similar messages are going to be of lesser and lesser importance. What is going to be more and more significant is individual success and earnings of competitors and of people connected with them. This applies both to athletes connected with individual sports as well as those connected with team sports. That individualization will lead to atomization and reification of individuals striving for success.

Reification will favour deepening of loneliness and alienation, and - as a consequence deformation and degradation of the personality. It will be facilitated by increasing instrumentalisation of the body and health and, as a result, a more and more traumatic character of sport - that is, an increasing number of severe injuries and chronic illnesses caused by them, an increasing number of internal conflicts, difficulties with finding one's own place in the family, with building lasting bonds with the closest social environment serving as a basis for identity.

Hence there is going to occur a situation characterised by Erich Fromm (a famous cultural psychoanalyst, who was earlier connected with the Frankfurt School) consisting in upsetting the internal mental structure of the subject who is involved in compulsive relations of a smaller or a greater social group. Needs generated by the abovementioned group cause upsetting of the internal mental harmony between striving for increased autonomy and maintaining of communication with the group. An excess of individual ambitions causes - and is going to contribute to - lower and lower approval of the closest circle of persons. It is going to be a reason for more and more general and unbearable mental discomfort, for more and more permanent and deepening loss of identification with the group, of increasing neurosis, which even poses the threat that foundations of mental and social health will be undermined (Fromm, 1966, pp. 77-90). 
The abovementioned deformation and degradation of personality will be experienced not only by injured athletes but also by perpetrators of their suffering, because they will live in a mutually contradictory world based on an ambivalent axiological structure and on mutually exclusivehierarchies of values, which generate mental discomfort, conflict, neurotic states of mind. On the one hand, they will recognize universally abiding rules - care for both one's own and other persons' health - which are autotelically grounded and constitute an absolute value (in the Kantian sense of the word, Kant 1984, pp. 60-61). On the other hand - regarding various social expectation and their own benefits they will be ready to put success on the one scale and their own and their rival's health (treated in an instrumental way) on the other.

Fouls, injuries lead to chronic illnesses and pose a threat of losing health for ever. From that viewpoint, they reflect the fall of humane values of sport - of its Olympic and gentlemanlike roots. This applies to, among others, so-called tactical fouls which are taught during training, aggression on the sports field, intimidating rivals before and during competitions. A person who decides to act in such a way must be conscious that he is walking on "a thin rope" and is exposing himself to similar activities by the opponents. Such conduct is going to increase and to give impetus to a spiral of more and more sophisticated and harmful mutual influences.

The reason for increasingly traumatic character of sport will indubitably be increasing aggression - both that permitted and that not permitted by abiding regulations. This is confirmed by A. Fąfara's and B. Karolczak-Biernacka's research (Karolczak 2000, no. 7-8, p. 6). In their opinion, aggression in sport increases continuously. They think that one of reasons for that phenomenon is an aspiration for making sports spectacles more attractive. It is achieved by creation of rigorous conditions of start and play, including regulations obliging for fast, aggressive actions, for fierce fight.

The abovementioned description is right, although I cannot find a clear statement of whether it is a positive, or a negative phenomenon. I have the impression - maybe a false one - that the abovementioned psychologists rather regret that progressive situation. My opinion in that respect is rather ambivalent. I positively evaluate the fact that interest in sport as a form of spectacle increases more and more quickly, that regulations are made more precise and perfect in order to maximise attractiveness of the sports spectacle in the future. That is because of the fact that it stimulates coaches and athletes and is going to favour improvement of qualifications and skills, technical and tactical competences. Athletes' and coaches' motivation for greater activity before and during competition, for aggressive behaviours permitted by regulations (necessary, purposeful, etc), which enhance expression and saturate the spectacle with a greater and greater dose of emotions, is going to increase. That type of aggression is and will be by all means desirable (Kosiewicz 2009).

The connected mental stress and social, club, financial or political pressure will also more and more often stimulate and motivate forms aggression which are not permitted by regulations, condemnable, which do damage to rivals, which are evidence of striving for victory at any cost and which undermine the highest value of sport - the human being. Admittedly, sport has been created for him - to realize his dreams, expectation and needs (Kosiewicz 2005, pp. 316-325), but that fact will be interpreted first of all in an egoistic way. The notion of the human being in sport will be applied by an individual mainly to himself: understood in an individual and not a general way. The subject and the absolute value (according to that self-seeking interpretation) will, unfortunately, become only a given athlete for himself, whereas others - contrary to Kant's categorical imperative and to a greater and greater (maybe even a dramatic) degree - will be treated by that subject in an instrumental, objectifying, reifying way; that is, as a relative value (Kant 1984). The abovementioned others (a rival, a fellow athlete from the team, a coach or an owner of a club) will be used as a means to an end: a stage, a level or an instrument facilitating achievement of variously understood sports success. 
Nota bene, forms of aggression which are not permitted by the regulations have no sports character - neither from the formal, nor from the essential viewpoint, in spite of the fact that they take place during a sports spectacle, because such forms of aggression are directed against regulations of a given sport and hence against a given sports activity, which is just defined - in a situation of smaller or greater entanglement - by principles and rules stipulating its essence, identity, character, qualities and principles of rivalry. It is also directed against specific and permissible forms of movement - which are connected with that definition - and which are characteristic for a given sport (Kosiewicz 2009a).

Taking into account the abovementioned conclusions, it may be proclaimed that the two forms of aggression, attracting audience and favouring development of that form of the spectacle, are going to become even more intense in the sports spectacle. It refers to sports aggression - that is, positive aggression (resulting from the regulations). This applies also to the opposite behaviour; that is, to nonsports, negative aggression, which should not appear in sport, because it is not permitted by regulations and, from that formal viewpoint, has non-sports character. The development of the first is recommendable, whereas the second should be limited to a minimum. However its elimination will never be - according to my opinion - possible. Quite the opposite: it is going to grow significantly.

Aggressive behaviours, both those permitted and not permitted by the regulations - will become the dominating component of sports expression in the future. And greater interest is going to be aroused by those forms of aggression which are not permitted by regulations: among others, because of their aleatoric - less predictable, more dramatic and even tragic in its consequences - character.

Regardless of the fact of how both forms of aggression are judged - whether they are approved or punished - both of them, as stimulating motivations for the sports confrontation, are going to increase sports injuries, which may be condemned or not from the viewpoint of existing or future regulations. Of course, every injury - regardless its cause, kind of aggression - is harmful for health and testifies against sports activity (Kosiewicz 2009a).

\section{Doping in the future}

Unfortunately, prohibitions generate a "grey area". If the prohibition of doping becomes even more severe, that area will grow. Technologies of production and distribution - well camouflaged and difficult to uncover - will be developed. It will be more and more difficult to protect athletes from doping and results of its influence will be considerably varied regarding its harmfulness.

Forbidden doping is - and will be - especially dangerous - when applied by non-professionals, athletes lacking medical knowledge. Then there is a risk that harmful, life-threatening drugs will be taken. An especially alarming phenomenon is giving forbidden drugs - openly or non-openly - to children and sports youth, who are unaware of their negative influence. I am of the opinion that that phenomenon - so characteristic for East German and Soviet sport - will continuously decrease in the future. However, I do not have any data which would justify such a prophecy. I think only that social pressure concerning that issue - and taking into account its humanitarian and moral aspect - will be so strong and absolute that it will enforce protection of the youngest athletes against degradation of their health.

I am more pessimistic about doping of adults - especially because natural sports scientists sound the alarm that that phenomenon is growing. Drugs are taken - on a large scale - also by people practising amateur sports: for example in body building centres, fitness clubs, etc. An opinion that it is easier to enlarge muscle mass and to "sculpt" a harmonious beautiful figure using pharmacological means than by hard, long-lasting training has become common and is going to become even more 
common in the future. Neither other sports are free from that plague.

I am of the opinion that the only way to take control of that forbidden practice is to legalise it. Otherwise it will be impossible. Its co-creators and participants - pharmacologists, physicians, sports managers, coaches and athletes - will be always one step ahead with their innovations. They will invent such preparations which will be impossible to be detected at the beginning.

Generally accessible doping would liquidate amateurism and dilettantism. Thanks to that, it would be professionally directed and controlled. All athletes - both those from the field of highly competitive sport as well as from sport for all - would have the same offer and possibility of making use of it. They would make a choice according to their own scale of values. They would not violate abiding pharmacological-medical norms concerning that issue and the principle of equal chances. They would make use of their health according to their own discretion without moral anxiety or risk of disqualification.

\section{Alcohol and nicotine in sport}

Alcoholism and nicotinism are rooted in social deviations as such and are not connected with sport in an essential or an organic way. In the future they will probably disappear as strictly sports problems. They will have only individual and accidental - and not social and general - character. They will only be a proof of situation-related braggadocio, a form of celebration of victory, an individual or a collective attempt at neutralizing various forms of stress. Athletes will give up alcoholism and nicotinism as those forms of social deviation which are utterly reluctant from the instrumental point of view aimed at sports success.

\section{Poaching and corruption}

The abovementioned prohibition of doping of children and youth - motivated, among others, by health-oriented and moral reasons - is not going to include poaching of the most talented athletes in that age group. That phenomenon, in my opinion, will become even more common and so-called headhunters will be stimulated by greater and greater benefits. They will maintain hypocritically that the phenomenon does not cause any negative results, for example in the field of mental health, whereas - as a matter of fact - poaching of children and youth may cause even drastic and irreversible results: havoc in the realms of human relations, social and mental health.

Persons professionally dealing with poaching treat - and are going to treat - talented youth mainly in an instrumental way, heedless of their educational needs. They "uproot" young persons from their natural school and family environment, tempting them with high profits resulting from sports success. This is going to end with disturbance of the world of values and family relations, which have been carefully created by various educational institutions. Businessmen working in sports clubs are guided - and are going to be guided - mainly by their own interest, their benefits: the money they invest is, first of all, to bring them income.

Unfortunately, this is going to be the most important imperative of their activity. Progressing commercialism - and the connected thirst for surplus value - will activate wolfish rules of the market in that respect.

Top sport indubitably brings high profits, which are achieved not only by athletes and coaches but also by organizers of events, producers of equipment, etc. There is a lot of money around sport and there are a lot of people who want to get it. It is pointed out that phenomena of corruption and 
poaching are especially dangerous. The first of them refers to bribing referees and organizers of events, as well as athletes and coaches standing in the way of the success of a given athlete or a team. It was commonly regretted that this also affected the International Olympic Committee in connection with endeavours of various states and cities aimed at holding summer or winter Olympic Games.

I am sure that the discussed phenomenon will never be eradicated. Growing sports investments and greater and greater incomes resulting from their existence will always stimulate, to a lesser or to a greater degree, making a fortune by means of it or thanks to it. If even death penalties which are applied to persons producing and distributing illegal drugs in many countries do not cause eradication of drug addiction, all the more lenient punishment of corruption is not going to prevent that practice either. The scale of that phenomenon will probably grow - similarly to profits connected with it.

\section{Social frustration and fans' aggressive behaviours}

Sport has become a catalyst facilitating manifestations of aggression by persons who in social life are permanently deprived of the sense of their own value. This refers especially to frustrated football fans - persons not so much from the dregs of society as from its lower classes, young people who are unable to find their own place in life. Gathered in a group they feel their "power". That is why they try to influence the situation in the stadium and out of it. The fact that - because of disturbances and hooligan excesses - they are for some time at the centre of social attention turns them (from their own viewpoint and from the viewpoint of their "pals") into a peculiar kind of heroes. They are shown by TV during the match and after it, they are interviewed, etc. They are sure that they constitute an indispensable part of the sports spectacle, that they co-create it by putting up a real fight against those fans who are their opponents and opponents of their favourites. If the fight of their sports idols is only symbolical and conventional, based on regulations and rules, they fight seriously using means which may mutilate or kill. They live on the margin of other cultural and civilisational events, waiting for their five minutes, for a public demonstration of unpunished aggressive collective power, for spectacular devastation of sports halls, stadiums and their surroundings, for street brawls with police. Sport has helped to focus their aggression and facilitate its expression, it became a compensatory mechanism neutralizing, in an illusory and substitutive way, their frustration, their lack of the sense of their own value and needs which were not satisfied in other fields.

Many countries managed to bring that social evil under control by consistent combined influences connected with activities of fan clubs, efficient monitoring of sport facilities, introduction of identity cards and registering hooligans, safety barriers between particular sectors for fans and between the spectators and the stadium, as well as with body searches of persons suspected of carrying in alcohol and means used in brawls before entering the stadium. However, according to philosophers, sociologists and social psychologists dealing with sport, preventive activities of such a kind are not proper and sufficient, since they have features of a symptomatic - and not of causal - treatment. It is because they do not treat real causes of that social disease looking for a spectacular vent. It is not enough to neutralize superficial symptoms of the disease which eats away at groups of youth who live in postindustrial and postmodern society being deprived of the sense of their own value in a "physiotherapeutic way" (that is, with the use of the police baton). Such endeavours may contribute to an even more dangerous explosion of their dissatisfaction in an unknown form and in unknown time (Kosiewicz 2001, s. 40-42). 


\section{Conclusions}

Conclusions concern two questions:

Will the abovementioned deviations and social dangers exert a negative influence on development of sport and interest in sport in the future?

Will those deviations and social dangers exert a negative influence on the general image of sport, its qualities, essence, sense and expectations, needs, aspirations and dreams which are connected with it?

Firstly, I am of the opinion that - taking into account the final balance of their influences - none of the deviations and social dangers will have a negative impact on development of sport and interest in sport. The majority of them may even, paradoxically, contribute to their stimulation.

Nota bene, such dangerous and socially harmful phenomena as alcoholism and nicotinism - are going to have little influence on increasing or decreasing interest in sport as such - in its highly competitive form - because they are marginal phenomena among athletes.

Social determinants of political, ideological, religious, racial and similar character are going to influence the form and assumptions of rivalry and the character of the sports spectacle less and less. National, continental and world sports events will usually transform into cosmopolitan undertakings. They will be based on international teams and they will promote both team and individual success regardless the abovementioned determinants.

Universal commercialization of sport - which until recently was often treated as a necessary evil - has stimulated and is going to stimulate development. It will intensify even more common interest in sport - and especially in the sports spectacle. On the other hand, growing obligations - caused by growing expectations of demanding employers paying great honoraries and bonuses and rich sponsors, who are hungry for success and ruthlessly settle accounts in the face of failures - will surely contribute to atomization, reification and alienation of athletes, and to deformation and degradation of their personalities, although those phenomena need be neither necessary, nor common.

The mental state of idols, protagonists of sports events presented on the front pages of newspapers and in various electronic media - their possible anxieties, neuroses, disturbances of personality and social health - will intrigue more and more. They will arise curiosity and stimulate the interest of viewers of sports events. Fans will be fascinated not only by athletes' internal conflicts, which will be appropriately publicized, but also by their external difficulties with building lasting bonds with their closer and more distant social environment - bonds which could serve as foundations for their identity.

Fans will pay attention neither to reasons of mental and social deviations, nor to instrumentalisation of the body and health. They will rather be interested in their specific resonance in a spectacular increase in the number of fouls and injuries, and in their influence on dramaturgy of the spectacle, composition of a team, prospects for future games. Possible irksome and lasting character of treatment of severe injuries and chronic traumas will be regarded almost exclusively from the abovementioned point of view.

Attractiveness of sports spectacles will be enhanced by various forms of aggression: that permitted by the regulations and that which is not permitted by them; bodily, mental and relational; in the field and out of it; verbal, printed, in the form of film and other visual documentaries (presented, for example, in the mass media).

Negative dope, harmful for health, will develop and the grey area will grow, until the phenomenon is legalized. It is not sure, however, whether it happens at all. Nota bene, doping as such 
will exert neither positive, nor negative influence on development of sport as such. Increasing interest - of moral, customs-related and penitentiary character - will certainly be the main reason for exposing and exploding of scandals and affairs connected with doping.

Similarly little influence on development of sport as such will be exerted by poaching, corruption or social frustration of fans. These will be condemned by viewers of sports events, whereas inside sport - that is, within the milieu dealing with professional sport - they will be more and more often treated with tacit consent. But when the discussed phenomena are uncovered and publicized, they will be ruthlessly condemned as very harmful from the social viewpoint, similarly to what happens nowadays. Admittedly the abovementioned phenomena are reprehensible, but they will indubitably contribute to temporal (during the medial exposition of the peculiar - because hypocritical - crisis of values) increase in interest in sport, and especially in particular persons and sports involved in them.

Secondly (this is the answer to the second of the abovementioned questions), also in this case the discussed deviations and threats will not influence the image of sport, its qualities, essence and sense, or expectations, needs, aspirations and dreams which are connected with it, in a negative or a destructive way - except for shorter or longer periods when some institutions, persons or phenomena are pilloried by public opinion.

The image of sport - or of particular sports - will not suffer in the long run, similarly to how the opinion about the society is not changed only on the basis of information of periodically happening crises or social deviations. Crises or social deviation may appear in each democratic society, they have smaller or greater administrative, civil or penal consequences. However, it does not influence negatively the whole image in the long run. Nota bene, social deviations - both deviations as such and deviations in sport - are admittedly periodical but often long-term states, characterized by numerous recurrences and metastases.

Neither I am of the opinion that deviations and social threats found in sport exert a negative influence on expectations, needs, aspirations and dreams connected with it. The latter are rooted and historically established in almost all known civilizations. Sport as a form of rivalry will constantly grow and become more and more widespread, because rivalry and the need for success as such are idiogenetically determined: they are elements of human nature, similarly to the need for fitness and physical perfectionism. Hence both expectations as well as their special form of dreams will always accompany sports activity in particular sports.

The answer regarding sport based on high qualifications - its qualities, essence or sense - is a different matter. On the basis of the abovementioned statements it is possible to conclude that - in spite of influence of social deviations - both its ontological (qualities, essence) and epistemological (sense) attributes will not be changed either. This refers both to sport as such and to particular sports.

Are there any factors which can change the abovementioned attributes of sport in the future? I can point to at least two possibilities:

Firstly, qualities, essence and sense of sport as such are, and will always remain, unchanging, such as Plato's unchanging ideas concerning material and abstract beings. In the realm of abstract beings this refers, among others, to good, beauty, love and just to sport: sport as a general idea.

Secondly, the abovementioned attributes may, however, change in the field of particular sports and they will change. The discussed qualities, essence and sense of definite sports are included in their particular definitions. They are expressed in the most direct and precise way by their principles, rules or regulations (Kosiewicz 2005). At the beginning they were shaped in an intuitive way. Nowadays 
their modification can be forced by, for example, TV viewers' expectations. Because of them there have been introduced changes in, among others, volleyball (e.g. those concerning counting points and the five-set tie-break in order to shorten the match) or in tennis (where a tie-break - in order to speed up the course of rivalry - was also applied, but in each of the played sets).

Moreover, in the future sport may change its expression - and, hence, qualities (but not essence and sense) - for example, under influence of improving technology. That issue has been thoroughly and excellently presented by S. Loland at one of the philosophical conferences. Of course, metamorphoses will happen in particular sports and not in sport as such.

In the future sport will be always more differentiated than nowadays, because there will certainly appear new, more or less fascinating, sports, which are difficult to define now. Nowadays, from the existing sports, there are emerging, for example, beach volleyball, 7-person handball (as opposed to 11-person handball), 7-person rugby or hall and beach football.

In the future the character of sport will be changed also by new solutions concerning sports spectacles. It refers also to transformations connected with world, European and national tournaments and cups.

My reflections on sport in the future are focused, first of all, on possible influence of deviations and social dangers. Hence I am not going to discuss in detail other possibilities and causes of other possible transformations.

\section{REFERENCES}

Aureliusz, Augustyn (413-426). De civitate Dei.

Hegel, G.W.F. (1990). Encyklopedia nauk filozoficznych/Encyclopaedia of the Philosophical Sciences/. Warszawa: PWN.

Fromm, E. (1966). Szkice z psychologii religii. /Sketches on Psychology of Religion/. Warszawa: KiW.

Kant, I. (1984). Uzasadnienie metafizyki moralności /Groundwork of the Metaphysics of Morals/. Warszawa: PWN.

Karolczak-Biernacka, B. (2000). Agresywny sport w agresywnym świecie /Aggressive Sport in Aggressive World/. Sport Wyczynowy/Competitive Sport/, no. 7-8.

Kosiewicz, J. (2001). Dilemmas and Perspectives of Contemporary Olympism. Hungarian Review of Sports Sciences. Special Issue, s. 40-43.

Kosiewicz, J. (2005). Is the Fair Play Principle the Highest Value in Sport? In J. Kosiewicz (Ed.) Sport, Culture and Society. Warsaw: Wydawnictwo AWF w Warszawie.

Kosiewicz, J. (2009a). Aggressive Behaviour in Sport. In Philosophy of Sport: From Methodology to Ethics. Warsaw: Wydawnictwo BK.

Kosiewicz, J. (2009b). On Methodology and Hypothesis. In Philosophy of Sport: From Methodology to Ethics. Warsaw: Wydawnictwo BK.

Møller, V. \& Nauright, J. (Eds.) (2003). The Essence of Sport. Odense: University Press of Southern Denmark. 